\title{
Could erlotinib treatment lead to acute cardiovascular events in patients with lung adenocarcinoma after chemotherapy failure?
}

This article was published in the following Dove Press journal:

OncoTargets and Therapy

5 June 2015

Number of times this article has been viewed

Tulay Kus

Gokmen Aktas

Alper Sevinc

Mehmet Emin Kalender

Celaletdin Camci

Department of Internal Medicine, Division of Medical Oncology, Gaziantep University, Gaziantep, Turkey
Correspondence: Tulay Kus Department of Internal Medicine, Division of Medical Oncology, Gaziantep University, TR-27310 Gaziantep, Turkey Email drtulaykus83@hotmail.com

\begin{abstract}
Erlotinib, an epidermal growth factor receptor and tyrosine kinase inhibitor, is a targeted drug that was approved for the treatment of non-small-cell lung cancers and pancreatic cancers. Targeted tyrosine kinase inhibitors are known to have cardiotoxic effects. However, erlotinib does not have a statistically proven effect of increasing acute cardiovascular event (ACE) risk. Preclinical studies showed that beta agonist stimulation among rats that were administered erlotinib led to cardiovascular damage. Thus, there would be an aggregate effect of erlotinib on ACE, although it is not thought to be a cardiotoxic drug itself. In this paper, we present two non-small-cell lung cancer cases that developed ACE under erlotinib treatment.
\end{abstract}

Keywords: erlotinib, lung cancer, myocardial infarction, EGFR

\section{Introduction}

The treatment of patients with cancer has radically changed over the past decades with the advance of targeted therapeutics. One of the targeted agents, erlotinib, is an epidermal growth factor receptor (EGFR) and tyrosine kinase inhibitor (TKI) that has demonstrated survival benefits and good tolerance in patients with non-small-cell lung cancers. It is the first-line therapy for patients with sensitizing EGFR mutations, and it is used following the progression of first-line treatment in patients regardless of sensitizing EGFR mutation status. ${ }^{1}$ Because targeted anticancer drugs were initially thought to affect tumors, but not normal tissues, in which the kinases were not constitutively active, the hope for targeted therapy was that it featured high efficacy with minimal side effects. However, clinical trials have revealed unanticipated side effects of the targeted therapies, especially cardiotoxicity. ${ }^{2}$ No cardiac toxicity has been reported with the use of erlotinib monotherapy. Therefore, we present two cases in which erlotinib was the probable causative agent of myocardial infarction (MI).

\section{Case I}

A 56-year-old male patient was admitted to hospital complaining of cough and fatigue in July 2014. The patient did not have a history of cardiac disease, diabetes mellitus (DM), hypertension (HT), dyslipidemia (DL), or a family history of cardiovascular events or smoking. Chest X-rays revealed pleural effusion at the right hemithorax. Positron emission tomography (PET)-computed tomography (CT) showed diffuse pleural thickening at the right hemithorax and hilar and mediastinal lymph nodes. Pleural biopsy and pleural fluid cytology revealed metastasis of lung adenocarcinoma. The patient was thought to have stage IV disease. EGFR mutation was not found and 
the $E M L-4 / A L K$ fusion gene was negative. First-line treatment with cisplatin $75 \mathrm{mg} / \mathrm{m}^{2}$ and pemetrexed $500 \mathrm{mg} / \mathrm{m}^{2}$ on day 1 was initiated for 3 weeks. After three cycles of chemotherapy, progression of the disease was detected and erlotinib $150 \mathrm{mg}$ /day (administered orally) was prescribed as a second-line treatment despite the absence of an EGFR mutation. Three months after the erlotinib treatment, PET-CT revealed stable disease and the patient was admitted to hospital complaining of chest pain. Electrocardiography (ECG) showed ST elevation on inferior derivations (acute inferior MI) and coronary angiography was performed. Eighty percent stenosis in the proximal right coronary artery segment was detected and a stent was placed in the right coronary artery.

\section{Case 2}

A 51-year-old male patient was admitted to hospital complaining of headaches in September 2012. The patient did not have a history of cardiac disease, DM, HT, DL, or a family history of cardiovascular events or smoking. PET-CT revealed a $65 \times 62 \mathrm{~mm}$ sized mass on the upper lobe of the right lung, as well as hilar and mediastinal lymph nodes, and involvement of the right adrenal gland. Metastatic lesions were detected on cranial magnetic resonance imaging, and the excision material was evaluated as metastatic adenocarcinoma. EGFR mutation was not found and the $E M L-4 / A L K$ fusion gene was found to be negative. First-line treatment with cisplatin $75 \mathrm{mg} / \mathrm{m}^{2}$ and pemetrexed $500 \mathrm{mg} / \mathrm{m}^{2}$ on day 1 was initiated for 3 weeks. After six cycles of chemotherapy, a partial response was achieved and maintenance therapy with three cycles of pemetrexed was continued. Progression of the disease was detected after the ninth cycle of treatment. Erlotinib treatment was initiated as a second-line treatment. The patient's disease was stable for 19 months, and he subsequently complained of chest pain. ECG revealed ST elevation on anterior derivations (acute anterior MI); $100 \%$ stenosis (thrombosis) of the left coronary artery and $80 \%$ stenosis of the circumflex artery was detected on coronary angiography. A coronary stent was implanted in the left coronary artery.

\section{Discussion}

The main mechanisms of cardiomyopathy of TKI can be divided into two general classes of toxicity. The first is "on-target" toxicity: the tyrosine kinase target that regulates cancer cell survival and proliferation also plays an important role in normal cardiomyocyte survival, and thus the patient exhibits myocardial dysfunction. The second is "off-target" toxicity, which is the result of the inherent nonselectivity of TKI and the trend toward "multitargeting"; this involves purposefully designing drugs to inhibit a broad range of targets that include kinases, which regulate both tumorigenesis and tumor angiogenesis. Although multitargeting may broaden the efficacy of an anticancer agent, the likelihood of toxicity would also increase. ${ }^{3}$ The cardiovascular side effects of TKIs include heart failure, cardiomyopathy, QT prolongation, acute coronary syndromes, myocardial injury, arterial thromboses, and HT. ${ }^{4}$

Targeted therapies such as antiangiogenic agents (sunitinib, sorafenib, and bevacizumab), which target vascular endothelial growth factor receptor, are associated with an increased risk of developing venous and arterial thromboembolism. ${ }^{5}$ But little is known about the risk of vascular events associated with targeting EGFR agents. The main toxic effects of these drugs are cutaneous (skin rash), gastrointestinal (diarrhea), and metabolic (hypomagnesemia). ${ }^{6}$

Petrelli et $\mathrm{al}^{7}$ performed a meta-analysis of 7,611 patients with respect to anti-EGFR agents, which are associated with a significant increase in the risk of venous thromboembolic events with cetuximab and panitumumab, but not with gefitinib and erlotinib. The EGFR inhibitor erlotinib has been evaluated in patients with pancreatic cancer. According to this study, ${ }^{8}$ myocardial ischemia and MI were observed with an increased rate in patients receiving erlotinib with gemcitabine, as compared with those treated with gemcitabine alone. According to another study by Senderowicz et $\mathrm{al}^{9}$ which compared gemcitabine and erlotinib with gemcitabine for the first-line treatment of locally advanced or metastatic adenocarcinoma of the pancreas, $2.3 \%$ versus $1.2 \%$ of patients experienced myocardial ischemia/infarction in both the combination arm and the gemcitabine-only arm, respectively. There is also relatively little data on the basic literature about this topic. Rockman et al ${ }^{10}$ showed that treatment of mice with erlotinib enhanced myocardial injury induced by isoproterenol infusion. The authors concluded that EGFR signaling may be effective in settings of catecholamine excess. $^{10}$

In our patients, the late toxicity of cisplatin might also be a triggering factor for ACE. Meinardi et al's study, ${ }^{11}$ which was designed to evaluate the cardiovascular risk of cisplatin in patients with young germ cell tumors after the completion of treatment, showed a $6 \%$ increase in cardiovascular events at the 10 -year follow-up. ${ }^{11}$ The pathophysiology and molecular basis of this effect remain elusive. However, unfavorable effects of ACE on conventional cardiovascular risk factors, such as body mass index, blood pressure, and changes in the 
lipid profile, have been shown, which explain the increased ACE risk observed, even if the molecular mechanism between cisplatin and these risk factors remains unsolved. The absence of DM, HT, and DL renders late cardiotoxicity of cisplatin an unlikely cause of ACE in our patients. We also cannot absolutely exclude the cardiotoxicity of cisplatin as a differential diagnosis. Our patients were stable regarding their lung cancer status, and they were in a low-risk group when evaluated for cardiovascular risk factors. Hence, erlotinib may be the causative factor of MI in patients with lung adenocarcinoma.

\section{Disclosure}

The authors report no conflicts of interest in this work.

\section{References}

1. Shepherd FA, Rodrigues Pereira J, Ciuleanu T, et al; National Cancer Institute of Canada Clinical Trials Group. Erlotinib in previously treated non-small-cell lung cancer. N Engl J Med. 2005;353(2):123-132.

2. Krause DS, Van Etten RA. Tyrosine kinases as targets for cancer therapy. N Engl J Med. 2005;353(2):172-187.

3. Chen MH, Kerkelä R, Force T. Mechanisms of cardiac dysfunction associated with tyrosine kinase inhibitor cancer therapeutics. Circulation. 2008;118(1):84-95.
4. Force T, Krause DS, Van Etten RA. Molecular mechanisms of cardiotoxicity of tyrosine kinase inhibition. Nat Rev Cancer. 2007;7(5): 332-344.

5. Choueiri TK, Schutz FA, Je Y, Rosenberg JE, Bellmunt J. Risk of arterial thromboembolic events with sunitinib and sorafenib: a systematic review and meta-analysis of clinical trials. J Clin Oncol. 2010;28(13): 2280-2285.

6. Zhang WQ, Li T, Li H. Efficacy of EGFR tyrosine kinase inhibitors in non-small-cell lung cancer patients with/without EGFR-mutation: evidence based on recent phase III randomized trials. Med Sci Monit. 2014;15(20):2666-2276.

7. Petrelli F, Cabiddu M, Borgonovo K, Barni S. Risk of venous and arterial thromboembolic events associated with anti-EGFR agents: a meta-analysis of randomized clinical trials. Ann Oncol. 2012;23(7): 1672-1679.

8. Monsuez JJ, Charniot JC, Vignat N, Artigou JY. Cardiac side-effects of cancer chemotherapy. Int J Cardiol. 2010;144(1):3-15.

9. Senderowicz AM, Johnson JR, Sridhara R, Zimmerman P, Justice R, Pazdur R. Erlotinib/gemcitabine for first-line treatment of locally advanced or metastatic adenocarcinoma of the pancreas. Oncology (Williston Park). 2007;21(14):1696-1706; discussion 1706-1709, 1712, 1715.

10. Noma T, Lemaire A, Naga Prasad SV, et al. Beta-arrestin-mediated beta1-adrenergic receptor transactivation of the EGFR confers cardioprotection. J Clin Invest. 2007;117(9):2445-2458.

11. Meinardi MT, Gietema JA, van der Graaf WT, et al. Cardiovascular morbidity in long-term survivors of metastatic testicular cancer. J Clin Oncol. 2000;18(8):1725-1732.
OncoTargets and Therapy

\section{Publish your work in this journal}

OncoTargets and Therapy is an international, peer-reviewed, open access journal focusing on the pathological basis of all cancers, potential targets for therapy and treatment protocols employed to improve the management of cancer patients. The journal also focuses on the impact of management programs and new therapeutic agents and protocols on

\section{Dovepress}

patient perspectives such as quality of life, adherence and satisfaction. The manuscript management system is completely online and includes a very quick and fair peer-review system, which is all easy to use. Visit http://www.dovepress.com/testimonials.php to read real quotes from published authors. 